\title{
On Definiteness and Information Trigger in Arabic
}

\author{
Marwan Jarrah \\ Newcastle University and University of Jordan \\ E-mail: m.a.s.jarrah@newcastle.ac.uk \\ Aseel Zibin (Corresponding author) \\ School of English Literature, Languages \& Linguistics \\ Newcastle University, Newcastle upon Tyne/England \\ P.O. Box: NE1 7RU, Percy Building, Newcastle University, Newcastle upon Tyne/England \\ Email: a.zibin@newcastle.ac.uk
}

Doi:10.7575/aiac.alls.v.7n.2p.55

Received: 07/11/2015

URL: http://dx.doi.org/10.7575/aiac.alls.v.7n.2p.55

Accepted: 15/01/2016

\begin{abstract}
The current research argues that definiteness in Arabic can be used for formal purposes. The definite article and the nunnation suffix $-n(\mathrm{NnnS})$ manage the information flow in the sentence through maintaining accepted informativity balance. Additionally, the study assumes that $\mathrm{NnnS},-n$, is not an indefinite article. Its main function is rather to stimulate the speaker to add information about indefinite nouns. The information triggered by the NnnS is labelled as 'balancing materials', whose aim is to restore sentence acceptability which degrades due to indefinite nouns. Balancing materials can be of two types: semantic and formal. When the speaker balks at adding either types of balancing materials, the definite article is used, instead. Here, the definite article resolves the tension of adding information about the indefinite nouns and refraining from doing so. These issues are supported by empirical evidence. With this new role of definiteness, new insights into some pertinent issues, including sentence building and translation are offered.
\end{abstract}

Keywords: Definiteness; information control; sentence acceptability; negative transfer; Arabic

\section{Introduction}

Many attempts have been made to explore the definiteness role in sentence production and comprehension within various schools of thoughts (cf. Kathryn Bock and Irwin 1980; Bock 1982; Gernsbacher and Hargreaves 1988; Clifton and Frazier 2004; Cornilescu and Nicolae 2012; and Despić 2015). For instance, Heim (1982) links definiteness with information givenness, whereas Löbner (1987) with semantic necessity. Fraurud (1990) argues that 'lexicoencyclopaedic' knowledge of the (head) noun must be recovered together with other available 'anchors' to examine how definiteness is interpreted. ${ }^{i}$ Such attempts have not passed unchallenged, though. Cross-linguistic approaches have given rise to a range of variations that abstract away from the traditional assumptions on definiteness role (Lyons 1999). New accounts have connected definiteness to, among others, specificity (Von Heusinger 2002), uniqueness (Roberts 2003), identifiability (Chen 2004), and ellipsis and reference tracking (Nariyama 2003). A further line of enquiry has shown that definiteness plays a role in syntax, most notably in relation to case assignment (cf. Belletti 1988; De Hoop 1996; Danon 2001, 2008).

Regarding Arabic, definiteness has been linked to discourse and givenness structure (Retso 1984; Belyayeva 1997; Dickins 2013). With a lot of controversies shrouding this link, one finds that an account of definiteness in Arabic is still far from complete. Pertinently, few studies have investigated meta-pragmatic-and-semantic functions of definiteness in Arabic. ${ }^{\text {ii }}$ Against these lines and following the current reasoning on the functions that definiteness can undertake (cf. Alexiadou 2009; Czardybon et al. 2014; and Despić 2015, among others), the current research argues that definiteness in Arabic is utilised for purposes beyond semantics or pragmatics.

The paper proceeds as follows: section 2 touches on some previous work on definiteness, indicating that definiteness has been largely deemed as a pragmatic device for discourse production and perception. Additionally, this section addresses some attempts tackling definiteness in formal terms. Section 3 provides an account of how definiteness is related to sentence derivation in Arabic. It explores the underlying relation between nunnation and definiteness loss on the one hand and between definiteness and the use of expletive expressions on the other. Section 4 proposes two implications of this novel analysis of definiteness on sentence informativity and negative transfer (which occurs in translation). Section 5 concludes the paper.

\section{Definiteness}

Although definiteness has been analysed for decades, no consensus on its role has been reached (cf. Hawkins 1978; Löbner 1985; Fraurud 1990; Von Heusinger 2002). No clear account of definiteness was made, leaving this side of 
linguistic theory subject to heated debate. In the following subsection, some of the salient studies conducted on definiteness are introduced and reviewed.

\subsection{Definiteness as a discourse building device}

For many researchers, one prominent function of definiteness is anaphoricity (Hawkins 1978; Sidner 1979; and Reinhart 1983). The general outcome of anaphoricity-based studies is that the definite article introduces a new referent or refers back to a referent which is already anchored in the previous discourse (or in the speaker's mind). As such, definite DPs stimulate the listener's previous knowledge and/or discourse; hence functioning as anaphors, e.g., the woman in sentence (1a). On the other hand, indefinite DPs are viewed as new information without an alreadyestablished referent, e.g., a woman in sentence (1b) (see, Heim 1982, among others). Definite DPs are counted as given information. ${ }^{\text {iii }}$

(1) a. The woman left.

b. A woman left.

DPs encode different types of information due to their (in)definiteness status. What seems problematic within this approach is how first-mentioned definite DPs, referring to entities not established in previous discourse context, are processed. For Hawkins (1978), such DPs are interpreted with reference to what he names as 'triggers' (other DPs related to the given definite DP). However, according to Fraurud (1990), Hawkins's (1978) use of 'trigger' is not valid because it implies mistakenly that first-mentioned definite DPs rely on other DPs previously-established in common ground. A glimpse at sentence (2) below demonstrates that the listener has to search for some connection to necessary information for interpretation of the DP 'the queen' outside the accompanying context. The existing trigger is not thus another DP as claimed by Hawkins (1978).

(2) The queen visits a school for children in need.

If sentence (2) is a headline in a Jordanian newspaper published in 2015, then the DP the queen refers to Queen Rania. This result follows from the assumption that the listener searches for some trigger to interpret the relevant DP. Due to the absence of such a trigger, he/she appeals to common ground of the sentence (cf. Hurford et al. 2007). The question suggesting itself here is: what is the role of the definite article in such cases? It seems that the definite article is not sufficient to interpret definite DPs.

Further studies on the topic postulated that definiteness role goes beyond anaphoricity. In this regard, Löbner (1985: 411) argues that the head noun of definite DPs encapsulates a functional concept. The head noun possesses some linguistic arguments that help to specify its referent. Here, arguments are divided into two types: situational and object arguments. The former refers to possible case scenarios in semantics, whilst the latter denotes states either explicitly or implicitly. To illustrate this point, consider the following sentences:

(3) a. The statue (in Venice) is remarkable.

b. The crown prince (of Jordan) likes football.

In (3a), the situational argument, in Venice, which is related to the definite DP, the statue, denotes a location. In (3b), the prepositional phrase, of Jordan, is viewed as an object argument that denotes a state explicitly. However, although Löbner's (1985) theory paved the way for a new approach to definiteness, his approach did not offer a plausible solution for uncertainties and confusion attached sometimes to definiteness (Fraurud 1990; Renaud 1996). Other recent studies have examined definiteness with reference to what they call 'anchors' identification' (e.g., Fraurud 1990; Von Heusinger 2002; Schumacher 2009; and Doran 2012). Under this approach, the reference of first-mention definite DPs is identified once some anchors related to the relevant DP are found. This relation between definiteness and anchors gives rise to an argument made by Von Heusinger (2002), who suggests that specificity is not synonymous with definiteness. Even indefinite DPs which are not referential can have a relative specific meaning when some anchor is established. Definiteness is not the sole factor in the search for referents; other factors including lexico-encyclopaedic knowledge related to the head noun and anchors contribute to the interpretation of DPs.

A further line of research on definiteness reveals that definiteness might have formal functions (i.e., beyond semantics) which are necessary for sentence grammaticality. In the next subsection, an overview of such attempts is provided.

\subsection{Formal/syntactic definiteness}

Danon (2001) argues that Hebrew provides evidence for the formal use of the definite article. The core of the argument is that verbs in Hebrew only assign inherent Case, whilst prepositions assign structural Case. ${ }^{\text {iv }}$ The object being definite is not due to a certain semantic-pragmatic factor, but due to the fact that a structural Case is needed, and there is no way of assigning this Case to the direct object only by a preposition such as et which must be followed by a definite entity: 
The presence or absence of et can now be reduced to the structural versus inherent case distinction: et is used because it assigns structural case, as opposed to the verb, which doesn't. In other words et doesn't really select a definite DP, it just happens that it isn't needed with indefinites, which receive inherent case from the verb. An advantage of such a reduction is that it turns an apparently arbitrary selectional restriction into a link between two formal, structural aspects of the syntax of DPs: structural case and formal definiteness. (Danon 2001: 1094)

Danon (2008) indicates that Semitic languages exhibit definiteness agreement in terms of number and gender. There is an obligatory definiteness agreement between DPs and their nominal modifiers. This obligation is a syntactic phenomenon whose explanation requires no semantic knowledge. Consider the following example, adapted from Danon (2008: 875):
(4) ha-tmunot
ha-xadašot
DEF-pictures
DEF-new
'The new pictures'

In sentence (4), the nominal modifier xadašot agrees with the head noun tmunot in definiteness. Although xadašot is definite, it neither selects a referent nor contributes to the semantic content of the DP. It follows that definiteness marking on nominal modifiers is purely formal.

\subsection{Definiteness in Arabic}

As hinted at above, studies that have addressed definiteness in Arabic claim that definiteness must be semantically interpreted (e.g., Belyayeva 1997). Other studies link definiteness with agreement, especially when it is assigned to nonnominal entities (Brustad 2000; Kremers 2003; Ryding 2005; and Almansour 2012; and Abdullah and Dejani 2014). Relevant here is the treatment of the nunnation suffix $-n(\mathrm{NnnS})$ as an indefinite article. One apparent evidence for their assumption is the complementary distribution between this suffix and the definite article ?al-. DPs which are not marked with the definite article can be marked with NnnS, and vice versa: ${ }^{\mathrm{v}}$
(5) Jtarait-u
(*?al-)kitaab-a-n
buy.PAST-I
book-ACC-NnnS
'I bought a book'

However, such an account has not been supported. Fassi-Fehri (1993, 1999, and 2000) suggests that the NnnS cannot be analysed as an indefinite article. Alternatively, he states that even though the noun marked with NnnS is interpreted as indefinite; NnnS should be taken as a possessive marker. Yet, no clear evidence has been furnished in support of this point, leaving the actual nature of NnnS blurred.

One of the issues heavily-disputed in the related literature on Arabic is the presence of the definite article with generic DPs (cf. Alexiadou 2005; Danon 2010; Nofal 2011; and Abu-Melhim 2013). Fassi-Fehri (2005) postulates that the definite article with generic DPs affects how such DPs should be interpreted. If the DP is preceded by a definite article, the given DP has a generic reading, as in (6a) below where the DP ?al?usuudu 'the lions' does not refer to any specific lion, but to the feline species in general. Conversely, if the DP appears free of the definite article, the DP has an existential reading, as in (6b) below where the DP ?usuudun refers to some lions.

$\begin{array}{lc}\text { (6) a. tazParu } & \text { 1-Pusuud } \\ \text { roar.3SF.PRESENT } & \text { the-lions }\end{array}$

'lions roar.'

b. taz?aru Pusuud-u-n fi-s-sahil

roar.3SF.PRESENT lions-NOM-NnnS in-DEF-plain

'Some lions roar in the plain.'

The interpretation of definite DPs is taken to be governed by the context in which they are used. Whether they are referential or not relies on the presence of an antecedent in the common ground of the sentence.

Nonetheless, no study has addressed why indefinite DPs must be suffixed with the NnnS which is followed in most cases by information obligatory for the acceptability of the given sentence. For example, if the PP fissahili 'in the plain' is deleted from (6b), the sentence is rendered unacceptable despite the fact that the PP fissahili functions as an adjunct, revealing information already known to be associated with lions.

\section{(7) ? tazParu Pusuud \\ roar.3SF.PRESENT lions}

'Some lions roar.'

Summing up, definiteness role in interpreting DPs in discourse has been debatable in the last few decades. Several studies maintained that anaphoricity is not by far the ultimate reason for definiteness trigger in discourse. As a result, 
definiteness has been investigated within other perspectives, including syntax. On the other hand, definiteness studies on Arabic engendered several controversies. The next section examines our approach that definiteness is a cognitionsatisfying tool.

\section{Definiteness beyond semantic-pragmatic necessity}

The current research argues for a deeper role of the definite article in the derivation process in Arabic. It explains how definiteness is used as a cognition-satisfying tool when the speaker balks at providing information to render his/her sentence more informative. This assumption is better presented if NnnS's behaviour is explained.

\subsection{NnnS's behaviour}

As seen in section 2.3, the notion whether NnnS in Arabic is an indefinite article or not has been addressed (e.g., Fassi Fehri 1993; Marogy 2004; and Hoyt 2008). Although such studies have brought inroads into the role of NnnS in Arabic, the use of this suffix and its inextricable relation with definiteness are still controversial. The main obstacle to understand the functions of NnnS is its peculiar behaviour vis-à-vis definite and indefinite DPs on one hand and the proper DPs on the other. Although this particle is suffixed to indefinite DPs, it can also be suffixed to proper nouns, which are definite on their own. Consider first the contrast between sentences in (8):

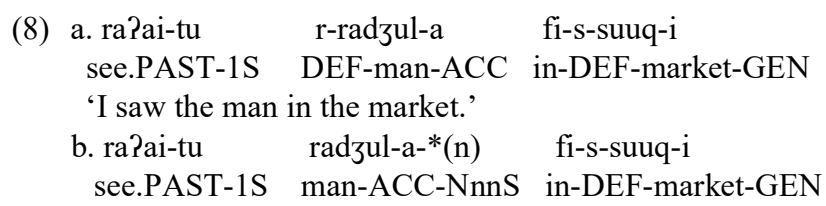

'I saw a man in the market.'

The DP radzul 'man' is definite in (8a). In (8b), it is indefinite; hence, it is suffixed with NnnS. One might argue that indefinite DPs must be suffixed with NnnS. However, this argument does not hold all the time. Indefinite DPs must not be suffixed with NnnS when appearing at the end of the sentence. For instance, if the DP suuq 'market' in (10a) is rendered indefinite, it must not be suffixed with NnnS.

(9)

$$
\begin{array}{lll}
\text { raPai-tu } & \text { r-radzul-a } & \text { fi-suuq-i- }\left(*^{*} n\right) \\
\text { see.PAST-1S } & \text { DEF-man-ACC } & \text { in-market-GEN-NnnS }
\end{array}
$$

'I saw the man in a market.'

A correlation between the non-necessity of NnnS and the position of indefinite DPs at the end of sentence must hold. This correlation can be taken in part as an argument against the assumption that NnnS is an indefinite article. Furthermore, the complementary distribution of the definite article ( $\mathrm{Pal}$ ) and NnnS does not justify the assumption that the latter is an indefinite article (Fassi Fehri 1993; and Ziadeh and Winder 2003). What supports this assumption is the suffixation of NnnS to proper nouns. Consider the following sentence:
(10) rapai-tu
mohammad-a-n
fi-s-suuq-i
see.PAST-1S Mohammad-ACC-NnnS in-DEF-market-GEN
'I saw Mohammad in the market.'

Although the proper noun Mohammad is definite on its own, NnnS is attached to it. It should be the case that there is something common by proper nouns and indefinite nouns being both suffixed with NnnS. It will become evident later that such connection between proper nouns and indefinite DPs is ascribed to the notion that such entities are headed by a null $\mathrm{D}^{\circ}$.

Additionally, what reinforces our assumption that $\mathrm{NnnS}$ is not a morphological realisation of indefiniteness in Arabic is its behaviour in conjunction with construct-state nominals. In Arabic, there are two realisations of definiteness: synthetically (by virtue of prefixing the definite article -?al to nouns) or analytically where an indefinite DP is annexed to a definite DP as in (11a) or to a proper noun or as in (11b) (The annexed elements are bracketed).

In such analytic constructions, the resulting constructs (the annexed indefinite DP and its associate, the definite DP) are termed as 'Construct-state Nominals', which are treated as one constituent (Borer 1999; Siloni 2002; Shlonsky 2004; Al-Shaer 2014). Here, NnnS cannot be attached to the annexed indefinite DP:

$$
\begin{array}{llll}
\text { ðahab-tu } & \text { Pila } & \text { [mathaf-i- }\left({ }^{*}\right. \text { ) } & \text { 1-madinat-i] } \\
\text { go.PAST-1S } & \text { to } & \text { museum-GEN } & \text { DEF-city-GEN }
\end{array}
$$

'I went to the city museum.' 
However, NnnS is neither permitted on the definite associate of the construct unless it is a proper noun:

\begin{tabular}{|c|c|c|c|c|}
\hline ðahab-tu & Pila & [bait-i & khalid-i-n] & Pal-kabiir-i \\
\hline go.PAST-1S & to & house-GEN & Khalid-GEN-NnnS & DEF-big-GEN \\
\hline
\end{tabular}

When the associate of the construct-state nominal is indefinite, NnnS can be attached to it rather than the head noun:

$$
\begin{array}{lll}
\text { haaða [qawl-u- }\left({ }^{*} n\right) & \text { ћaqq-i-n] } & \text { s }^{\text {faaPib }} \\
\text { this speech-NOM } & \text { right-ACC-NnnS } & \text { reasonable } \\
\text { 'This is a reasonable true speech.' } &
\end{array}
$$

If $\mathrm{NnnS}$ is an indefinite marker, the reason why it is blocked from being attached to the indefinite head of the constructstate nominal, whether the associate is definite or not, is not clear. Examples (11-14) also indicate that NnnS can be attached to proper nouns and indefinite DPs, alike. They also make clear that NnnS comes at the end of the construct state nominal where nominal modifiers and adnominal complements are located.

Before addressing these observations, let us show how definiteness in Arabic can be meta-semantically or pragmatically triggered. Consider sentence (15) where the DP mudztamas 'community' and qaad'i 'judge' do not refer to any particular community or judge. Following related literature, although both of them are definite, they are generic in referentiality.

$$
\begin{array}{llcc}
\text { laa } Z^{\complement} \text { ulm-a } & \text { fi-l-mudztamaS-i } & \text { Piða kaan } \\
\text { no injustice-ACC } & \text { in-DEF-community-GEN } & \text { if } & \text { was } \\
\text { l-qaad } & \text { Saadil } & & \\
\text { DEF-judge } & \text { fair }
\end{array}
$$

Given that both DPs i.e. mudztamaS 'community' and qaad'i 'judge' are generic, sentence (15) should be interpreted as follows:

There is no injustice in any community if any judge is fair.

However, two counter-arguments for this interpretation are in order. Firstly, although the DP $z^{\varsigma} u l m$ has a generic reference like the DPs mudztamas 'community' and qaad' $i$ 'judge', no definite article is realised on it. ${ }^{\text {vi }}$ Secondly, the DPs mudztamas 'community' and qaad'i 'judge' are not similar in generic-hood. Whereas the former has a broad general reference, the latter has a less-restricted generic reference bounded by the referentiality of the former:

(17) There is no injustice in any community if any judge in that community is fair.

The generic reference of the DP qaad $\varsigma_{i}$ 'judge' must be associated with what is picked out in discourse for the DP mudztamas 'community'. This association is important because it dispenses with any reading associating all judges with a particular community. The following figure illustrates this association:

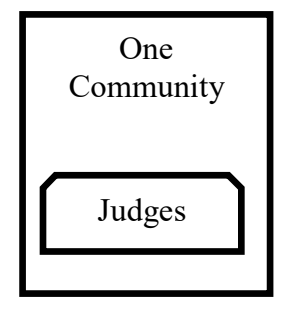

Figure 1. Generic-hood of the DPs mudztamas 'community' and qaad'i 'judge'

What supports our contention is that the assignment of the definite article to generic DPs varies cross-linguistically. There is no unanimous mechanism exhibited by languages to use the definite article in conjunction with generic DPs. Danon (2001) observes that the use of the definite article with generics varies cross-linguistically in a way that has no possible effect on interpretation. Spanish or French use definite articles with non-count generics unlike English. For instance, when the English sentence in (18a) is juxtaposed with its translation in Arabic in (18b), it appears that the word 'fire' has a different status of definiteness in both languages albeit the same degree of generic-hood, i.e. indefinite in English but definite in Arabic. 
(18) a. When fire starts to burn, it starts to spread.

$\begin{array}{cccc}\begin{array}{c}\text { b. Sindama } \\ \text { When }\end{array} & \text { stabda?u } & \text { n-naar-u } & \text { bil-PiftiSaal-i, } \\ \text { fa-Pinna-ha } & \text { tantafiru } & \\ \text { then-that.it } & \text { speard.3SF.PRESENT }\end{array}$

One significant point here is that the attachment of the definite article to generic DPs can be dispensed with if existential expressions are added. For instance, if the existential expression hunaaka 'there' is added to a sentence having a generic DP that is attached to the definite article, it is not obligatory for the generic noun to retain the definite article. Compare the following sentences:

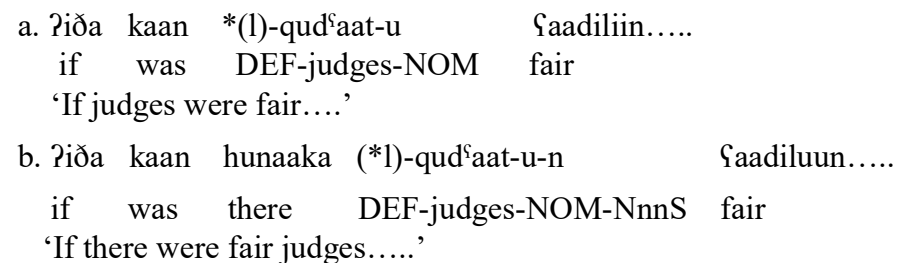

In case the definite article is omitted, the existential expression must be inserted and NnnS is suffixed to the end of the associate DP, as in (19b). The question here is: why adding existential expressions lessens the need for the definite article in such cases. Since the addition of a dummy existential expression is formally called for (i.e., to fill SpecTP forced by the EPP), it follows that the addition of the definite article can be formally-triggered as well.

Against these observations, we argue that when one noun is used indefinitely, Arabic makes available NnnS as a device to stimulate the speaker to add information about this noun. This assumption can account for the loss of NnnS at the end of sentences. Under this analysis, NnnS is an information-stimulant device, given that the use of indefinite DPs disturbs sentence informativity (cf. Enç 1991 and Ionin et al. 2011). As long as the main objective of sentences in particular, and communication in general, is informativity (Peti-Stantić 2013), using indefinite DPs diminishes sentence informativity. Once an indefinite DP is used, there should be some way to stimulate the speaker to add information about the given DP so the required level of informativity is obtained. In our terms, NnnS is the device dedicated for achieving this goal. The use of NnnS is thus governed by the definiteness status of the relevant DP, i.e. if the DP is definite, NnnS is not triggered. However, when the DP is used indefinitely, NnnS is triggered and thus information about the indefinite DP is called for. We label any materials (prepositional phrases, nominal modifiers, etc.) motivated by this specific need as 'balancing materials'.

\subsection{NnnS as an information trigger}

The speaker has three ways to meet NnnS's requirement to add balancing materials. Firstly, he/she might add what we call 'formally-triggered information' (FTI). Such a type of information has no significant value to the propositional content of the given sentence. Consider the following sentence:

$$
\begin{array}{ll}
\text { raPai-tu } \quad \text { radzul-a-n } & \text { fi-1-maad'i } \\
\text { see.PAST-1S man-ACC-NnnS } & \text { in-DEF-past } \\
\text { 'I saw a man in the past.' } &
\end{array}
$$

In sentence (20), although the PP filmaad ${ }^{\uparrow} i$ is redundant (i.e., its meaning is presupposed by the tense of the verb), its use follows from the presence of NnnS. FTI is hardly used in conjunction with definite DPs:

$$
\begin{array}{lcc}
\text { ? ra?ai-tu } & \text { r-radzul-a } & \text { fi-l-maad }{ }^{i} \\
\text { see.PAST-1S } & \text { DEF-man-ACC } & \text { in-DEF-PAST }
\end{array}
$$

'I saw the man in the past.'

Although FTI does not contribute to the propositional content in both sentences, its presence in the former is important. Secondly, the speaker might add balancing materials which do contribute to the prepositional content of a given sentence. Such information is called 'discourse pillars' (DisP) because discourse interlocutors are heavily contingent on them to yield actual information about the indefinite DP at issue. DisP includes any type of information with semantic or pragmatic value to the hearer. For instance, the PP fissuuqi 'in the market' in sentence (8a) (which is reproduced below for convenience) is a DisP inasmuch as it gives concrete information about the indefinite DP radzulan.

$$
\begin{array}{lcc}
\text { raPai-tu } & \text { radzul-a-n } & \text { fi-s-suuq } \\
\text { see.PAST-1S } & \text { man-ACC-NnnS } & \text { in-DEF-market } \\
\text { 'I saw a man in the market.' }
\end{array}
$$


The division of the information added by NnnS to FTI and DisP can be syntactically supported. Contrary to DisP, FTI is immobile. For example, consider the ungrammatical sentence in (23) where PP filmad $i$ is dislocated to the left periphery of the sentence:

$$
\begin{aligned}
& \begin{array}{l}
\text { *fi-1-maadsi } \\
\text { in-the-PAST-GEN }
\end{array} \\
& \begin{array}{ll}
\text { raPai-tu } & \text { radzul. } \\
\text { 'In the past, I saw a man.' }
\end{array}
\end{aligned}
$$

Since FTI does not encode any propositional content necessary for hearers, it cannot be topicalised or focalised. Their presence is demanded by NnnS's requirement to add materials about the indefinite DP. The existence of optional information preceded by indefinite nouns which is neither new nor important to the propositional content of a given sentence follows.

Thirdly, the speaker might add existential expressions as a response to NnnS. Such expressions only co-occur with indefinite DPs in Arabic.

$$
\begin{array}{lll}
\text { hunaaka/yuudzad } & \text { radzul-u-n } & \text { fi-s-suuq } \\
\text { there/be.3SM.PRESENT } & \text { man-NOM-NnnS } & \text { in-DEF-market } \\
\text { 'There is a man in the market.' } &
\end{array}
$$

Although the existential expressions and FTI do not contribute to the propositional content of a given sentence, they are important for the sentence to be processed. Cognition requires sentences to be informative. When one entity entering sentence derivation does not increase sentence informativity, cognition demands adding further information about this entity. Such a demand can be executed via attaching the information-trigger device, NnnS, to the end of this entity.

One significant question here is: since these two types of information (existential expressions and FTI) are not semantically or even pragmatically significant, why there are called for. Put it another way, neither existential expressions nor FTI can be clues to interpret indefinite DPs, how come that they are driven by an informativity-based requirement. Our answer to this question is that cognition is more concerned about existence of materials, regardless of their content. When the speaker might lack any information about the indefinite DP he/she uses, one way of getting around the demands of cognition is to add non-semantic materials whose mere presence is important rather than their semantic/pragmatic import.

When the speaker balks at adding balancing materials, he/she can make use of the definite article. In such cases, the speaker is not bound to add materials about the indefinite DP which has become formally definite as a result of adding the definite article. Subsequently, NnnS is not utilised and no balancing materials are thus triggered because cognition does not require adding new information for the entities that the speaker seems aware of (by virtue of the definite article). Under these circumstances, the definite article is used formally, and since no anaphoricity is intended, the generic reading (for the indefinite DPs defined formally) is generated. Thus, the need to add information about one entity is governed by the presence or absence of the definite article. The presence of the definite article is seen as evidence that the speaker is totally aware of what he/she is talking about.

Two last issues to tackle before winding up this section are, first, the use of NnnS with proper nouns, and second, the behaviour of the prefix $h a$ - in some Arabic dialects. Regarding the former, as is clear from the discussion above, NnnS can be suffixed to proper nouns which are definite on their own. This observation seems problematic for our analysis. However, there is no problem arising for our analysis if we stick to the notion that such nouns, even definite, need further information about them to be qualified as real definite entities by cognition. It is more or less ubiquitous that when using a proper noun in conversation, it seems important to tell the interlocutors more information about the proper noun. A single name can refer to many people (i.e., namesakes). Thus, more detail or information about this proper noun is needed. In order to attest this finding, one experimental study has been carried out. Recorded sessions for four participants whose native dialect is Jordanian Arabic were conducted (all of the sessions were conducted after gaining the permission of these four participants to carry out the task). The participants were asked to speak with each other using Jordanian Arabic about any topic related to some people they had some experience with. It turns out that when speakers come across one proper noun, they add some formation about this noun in order to make its identity clear. The following are some examples:

$$
\begin{aligned}
& \text { a. mhamamd Pax-i... } \\
& \text { Mohamamd brother-my } \\
& \text { ' Mohammad, my brother, .....' } \\
& \text { b. lamahit omar mSallim 1-midrasih.... } \\
& \text { saw.1S Omar teacher DEF-school } \\
& \text { 'I saw Omar, the school teacher,' }
\end{aligned}
$$

Proper nouns can then be regarded as entities which are short on information. The attachment of NnnS to them follows. The fact that proper nouns require further information to be provided by the speaker brings to mind another entity that stipulates the same requirement, i.e. indefinite DPs. It must be the case that the two entities have something in common, 
given that both can be suffixed with NnnS. This connection is revealed by appealing to the type of head of the relevant DP (null vs overt). The syntactic structure of both proper nouns and indefinite DPs demonstrates that they are headed by a null $\mathrm{D}^{\mathbf{o}}$, whereas definite DPs are headed by an overt $\mathrm{D}$. If this reasoning is on track, the reason why proper nouns are marked with NnnS follows directly. The lack of an overt head in proper nouns and indefinite DPs licenses the addition of further information by the speaker. In case the head of DP is occupied by the definite article, the presence of the latter prevents the provision of further information. As such, we assume that the demand of cognition to add further information about one DP is invoked once the resulting DP is headed by a null head. ${ }^{\mathrm{vii}}$

The second issue is concerned with the behaviour of the prefix ha- in some Arabic dialects, including Jordanian Arabic. ${ }^{\text {viii }}$ Following related literature on specificity (Fiengo 1987 and Ionin 2006), we argue that this prefix is a specificity marker. It is only used with a DP whose referent is specific. Consider the following example:

$$
\begin{array}{lll}
\text { lageet } & \text { ha-z-zalamih } & \text { bi-s-suuq } \\
\text { found.1S. } & \text { SPEC-DEF-man } & \text { in-DEF-market }
\end{array}
$$

'I found the man in the market.'

What bears on our argument is that this marker does not occur with a definite DP whose referent is generic.

$$
\begin{aligned}
& \text { Piðaa kaan (*ha)-1-qud }{ }^{\complement} \text { aa } \quad \text { Saadiliin..... } \\
& \text { if was SPEC-DEF-judges fair } \\
& \text { 'If there were fair judges.....' }
\end{aligned}
$$

The behaviour of the prefix $h a$ - demonstrates that the definite article might occur without a specific referent. We assume that the cases where this prefix does not accompany the definite article, the latter is used for purposes beyond semantic or pragmatic needs. However, more examination is needed to attest our assumption. We leave this issue open for future research.

Having introduced our account of $\mathrm{NnnS}$ and cognition-based function of definiteness, we move on to highlight some implications of this account.

\section{Implications}

\subsection{Definiteness and acceptability control}

When using the definite article, the speaker believes that the listener knows the specific referent of the DP to which the definite article is adjoined. Knowledge of such a referent is part of the common ground shared by the interlocutors (Von Heusinger 2002 and Chen 2009). Once the speaker utters one DP and the listener receives it, the latter attempts to retrieve the information relevant to the referent pertinent to the DP if the definite article is attached to it. The presence of the definite article triggers the engine of presupposition inside the listener's mind, making an inference about the DP in question (Abbott 2004). Under such circumstances, the listener realises that the speaker need not provide any further information, i.e. DisP, in order to ascertain that the listener has understood the speaker's message; hence, there is no need for foregrounding (cf. Belyayeva 1997; Keenan and Schieffelin 2011). The definite article only reinforces the retrieved referent of the DP attached to the definite article. Reasoning along these lines, it can be posited that the definite article serves as a block to the provision of further information about the definite DP in question. Although any sentence must be informative, a certain level of informativity must be maintained. When further information is added to a definite DP, the sentence informativity reduces its acceptability. In other words, the definite article restricts the required level of information about the definite DP.

Differently, if the definite article is not used with a DP, NnnS is called for to stimulate the speaker to add information about the indefinite DPs used in an attempt to restore sentence informativity. For the listener, the DP marked by NnnS is new information to which reference in the mind of the listener does not exist. Hence, upon hearing such a DP, the listener does not embark on searching for the referents of the indefinite DP. On the contrary, he/she assumes that further information from the speaker will follow to clarify the referent's identity; thus, exerting less effort in interpreting the speaker's message. As a result, NnnS plays a role in facilitating the communication between the speaker and the listener. Similarly, unlike the definite article, $\mathrm{NnnS}$ is seen as a means to trigger more information, enhancing sentence informativity. This correlation between information and definiteness articles and NnnP can be diagrammed as follows: 


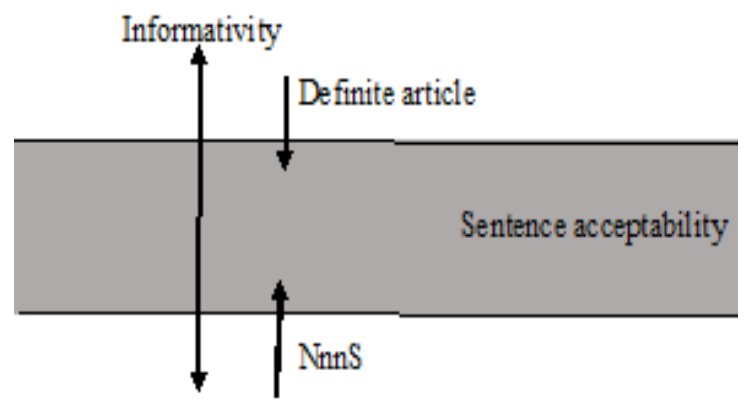

Figure 2. The role of NnnS and the definite article verses informativity

Figure 2 shows that when informativity goes down the allowed level of sentence acceptability, NnnS is employed to trigger the speaker to add information about the indefinite DPs. Such addition raises sentence informativity which is decreasing due to the indefinite DPs. Conversely, if informativity exceeds the allowed level of sentence acceptability, the definite article is used to block any addition of information about the definite DPs whose (austere) presence, e.g. without nominal modifiers, is enough to maintain sentence acceptability. In this light, both NnnS and the definite article in Arabic have the same ultimate goal in restricting sentence informativity within the limits sanctioned by its acceptability.

\subsection{Formal definiteness transfer}

Several studies indicated that Arab learners encounter problems when transferring the definite article to other languages like English (e.g., Kharma 1981; Khuwaileh and Shoumali 2000; Smith and Swan 2001; Crompton 2011; Harb 2014; Husni and Newman 2015). Following our discussion in section 3, this difficulty of translating the definite article into other languages emerges due to the conceptually-based use of the definite article in Arabic. Arab EFL learners assume that the presence of the definite article is fundamental for sentence acceptability. Hence, they neglect to acknowledge the incompatibility of the definite article and its function in the targeted language, falling in the trap of negative transfer (cf. Mohan and Lo 1984, Ellis 1994, Larsen-Freeman and Long 2014; Altakhaineh and Zibin 2014; Zibin and Hamdan 2014). ${ }^{\text {ix }}$ This type of transfer takes place when a structure in L1 is utilised in L2 inappropriately (Saville-Troike 2012). Following our argument, the definite article, when used non-anaphorically, is negatively transferred into L2, yielding a structure deemed unsuitable or even bizarre by native speakers of, say, English. In order to attest this finding, we conducted an experiment study, asking 40 Arabic learners of English to translate the Arabic sentence in (28a), 35 of them (87.5\%) translated the sentence with the definite article in English, as seen in (28b):

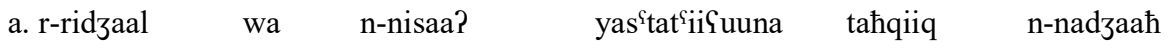

$$
\begin{aligned}
& \text { DEF-man.PL and DEF-women can.3PL.ACC attainment DEF- success }
\end{aligned}
$$

b. Both the men and the women can attain the success

The definite article is realised on the DPs men, women and success even though it is uncalled for, since those DPs are non-anaphoric. The formal definite article, which is required on meta-semantic/pragmatic grounds, turns out to be the main cause for this negative transfer.

\section{Conclusion}

In this study, we argued that not all instances of definiteness in Arabic are grounded within anaphoricity or generichood. Differently, the definite article, under certain circumstance, is driven so as to retain the definiteness balance of the sentence, which is realised through various types of what is called 'balancing materials'. Contrary to what has mainly been agreed upon in the relevant literature, we argued that NnnS is not an indefinite article. Arabic employs $\mathrm{NnnS}$ as a tool to stimulate the speaker to add information about indefinite DPs. This information might be FTI, DisP, or existential expressions, rendering the sentence more acceptable. Conversely, such information is blocked by the definite article that serves as an anti-information trigger, preventing cognition from requiring additional materials as it jeopardises sentence acceptability. It follows that when the definite article is present; NnnS is no longer needed. The use of NnnS with proper nouns has been attributed to the lack of information supplied by such nouns as they may refer to more than one individual. Lack of an overt D acts as a stimulant for cognition to require further information about the entity in question. The key factor behind the use of the formal definite article in Arabic revolves around sentence informativity, which is intertwined with its acceptability. Additionally, the study shows that the definite article used for cognition-satisfying needs is the underlying reason for the negative transfer of the definite article from Arabic into English. 
Acknowledgments

We are indebted to all participants who took part in the experiments. Additionally, we would like to thank both Abdel Rahman Altakhaineh and Murdhy Al-Shamari for their insightful comments on the earlier version of this paper. All remaining errors are ours.

\section{References}

Abbott, B. (2004). Definiteness and indefiniteness. In Horn, L. R., and Ward, G. (Eds.) The handbook of pragmatics (pp. 122-149). Oxford: Blackwell.

Abdullah, H., and Dejani, B. A. (2014). A Comparative Study on Definiteness and Indefiniteness in Arabic and Malay Languages. Dirasat Human and Social Sciences, 41(1), 436-452.

Abney, S. P. (1987). The English noun phrase in its sentential aspect. Doctoral dissertation, Massachusetts Institute of Technology.

Abu-Melhim, A. R. (2013). The Presence or Absence of Definiteness in the Native Language and Its Impact on ESL Learning. English Language Teaching, 7(1), 50-65.

Alexiadou, A. (2005). Possessors and (in) Definiteness. Lingua, 115(6), 787-819.

Alexiadou, A. (2009). On the role of syntactic locality in morphological processes: the case of (Greek) derived nominals. In Giannakidou and Rathert (Eds.), pp.253-280.

Alhaisoni, E., Jarrah, M. A., and Shehadeh, M. S. (2012). An investigation of evidentiality in the Arabic language. International Journal of Linguistics, 4, 260-273.

Almansour, A. H. (2012). A Phase-based Approach to the Construct State. Journal of King Saud University-Languages and Translation, 24(1), 23-34.

Al-Shaer, I. (2014). Arabic and English Genitive Constructions: A Corpus-based Contrastive Analysis of Patterns and Equivalence. Languages in Contrast,14(2), 163-190.

Altakhaineh, A., and Zibin, A. (2014). Perception of Culturally Loaded Words by Arab EFL Learners. International Journal of Linguistics, 6(3), 1-22.

Al-Jarrah, R. S., Abu Dalu, A. M., and Jarrah, M. (2015). A relevance-theoretical account of three Arabic pragmatic operators of concession in a political discourse. Lodz Papers in Pragmatics, 11, 51-76.

Belletti, A. (1988). The Case of Unaccusatives. Linguistic inquiry. 1-34.

Belyayeva, D. (1997). Definiteness realization and function in Palestinian Arabic. Amsterdam Studies in the Theory and History of Linguistic Science Series, 4, 47-68.

Bock, J. K. (1982). Toward a Cognitive Psychology of Syntax: Information Processing Contributions to Sentence Formulation. Psychological Review, 89(1).

Borer, H. (1999). Deconstructing the Construct. In: Johnson, Kyle, Roberts, I.G. 43-89.

Bowdle, B.F., and Gentner, D. (1997). Informativity and Asymmetry in Comparisons. Cognitive Psychology, 34(3), 244-286.

Brustad, K. (2000). The syntax of spoken Arabic: A comparative study of Moroccan, Egyptian, Syrian, and Kuwaiti dialects. Georgetown University Press.

Chen, P. (2004). Identifiability and Definiteness in Chinese. Linguistics, 42(6), 1129-1184.

Chen, P. (2009) Aspects of Referentiality. Journal of Pragmatics, 41(8), 1657-1674.

Chomsky, N. (1981). Lectures on government and binding. Dordrecht: Foris.

Chomsky, N. (1986). Knowledge of language. New York: Praeger.

Clifton, C., and Frazier, L. (2004). Should Given Information Come Before New? Yes and No. Memory and Cognition. 32(6). 886-895.

Cornilescu, A., and Nicolae, A. (2012). Nominal Ellipsis as Definiteness and Anaphoricity: The Case of Romanian. Lingua, 122(10), 1070-1111.

Crompton, P. (2011). Article Errors in the English Writing of Advanced L1 Arabic Learners: The Role of Transfer. Asian EFL Journal, 50(1), 4-35.

Czardybon, A., Hellwig, O. and Petersen, W. (2014). Statistical analysis of the interaction between word order and definiteness in Polish. In Advances in natural language processing (pp. 144-150). Springer International Publishing.

Danon, G. (2001). Syntactic Definiteness in the Grammar of Modern Hebrew. Linguistics, 39(6), 1071-1116.

Danon, G. (2008). Definiteness Spreading in the Hebrew Construct State. Lingua, 118(7), 872-906.

Danon, G. (2010). The Definiteness Feature at the Syntax-Semantics Interface. Features Perspectives on a Key Notion in Linguistics. 144-165. 
Despić, M. (2015). Phases, Reflexives, and Definiteness. Syntax, 18(3), 201-234.

Dickins, J. A. M. E. S. (2013). Definiteness, genitives and two kinds of syntax in Standard Arabic. Nicht nur mit Engelzungen: Beiträge zur semitischen Dialektologie. Festschrift fuer Werner Arnold zum 60. Geburtstag, 59-72.

Doran, R. B. (2012). Definiteness, specificity, and the multiple uses of demonstrative expressions. Doctoral dissertation, Northwestern University.

Ellis, R. (1994). The study of second language acquisition. Oxford University Press.

Ellis, R. (1994). The study of second language acquisition. Oxford University Press. Ingham, B. Najdi Arabic: Central Arabian (Vol. 1). John Benjamins Publishing.

Enç, M. (1991). The Semantics of Specificity. Linguistic inquiry. 1-25.

Fassi Fehri, A. (1993). Issues in the structure of Arabic clauses and words. Dordrecht: Kluwer.

Fassi-Fehri, A. (2005). Verbal and Nominal Parallelisms. Documents and Reports. 1-22.

Fehri, A. F. (2000). Distributing Features and Affixes in Arabic Subject Verb Agreement Paradigms. Amsterdam Studies in the Theory and History of Linguistic Science Series, 4, 79-100.

Fehri, Fehri, A. (1999). Arabic Modifying Adjectives and DP Structures. Studia Linguistica. 53(2). 105-154.

Fiengo, R. (1987). Definiteness, Specificity, and Familiarity. Linguistic Inquiry. 163-166.

Fraurud, K. (1990). Definiteness and the Processing of Noun Phrases in Natural Discourse. Journal of Semantics. 7(4). 395-433.

Gernsbacher, M.A. and Hargreaves, D.J. (1988). Accessing Sentence Participants: The Advantage of First Mention. Journal of Memory and Language, 27(6), 699-717.

Harb, M. A. (2014). A Closer Look at the English Article System: Internal and External Sources of Difficulty Revisited. International Journal of Linguistics, 6, 87-101.

Hawkins, J.A. (1978). Definiteness and indefiniteness: a study in reference and grammaticality prediction. Croom Helm Ltd.

Heim, I. (1982). The semantics of definite and indefinite noun phrases. University of Massachusetts Amherst.

Hoyt, F. (2008). The Arabic noun phrase. The Encyclopedia of Arabic Language and Linguistics. Leiden: Brill.

Hurford, J. R., Heasley, B., and Smith, M.B. (2007). Semantics: A coursebook. Cambridge University Press.

Husni, R., and Newman, D. L. (2015). Arabic-English-Arabic-English translation: Issues and strategies. Routledge.

Ionin, T. (2006). This is Definitely Specific: Specificity and Definiteness in Article Systems. Natural Language Semantics, 14(2), 175-234.

Ionin, T., Montrul, S., and Santos, H. (2011). An Experimental Investigation of the Expression of Genericity in English, Spanish and Brazilian Portuguese. Lingua, 121(5), 963-985.

Jarrah, M. A. (2016). Explicit-implicit Distinction: A Literature Review. Advances in Language and Literary Studies, 7(1), 175-184.

Kathryn Bock, J., and Irwin, D. E. (1980). Syntactic Effects of Information Availability in Sentence Production. Journal of Verbal Learning and Verbal Behavior, 19(4), 467-484.

Keenan, E. O. and Schieffelin, B. (2011). Foregrounding referents: A reconsideration of left dislocation in discourse. In Annual Meeting of the Berkeley Linguistics Society (Vol. 2).

Kharma, N. (1981). Analysis of the Errors Committed by Arab University Students in the Use of the English Definite/Indefinite Articles. IRAL-International Review of Applied Linguistics in Language Teaching, 19(1-4), 333-345.

Khuwaileh, A. A. and Shoumali, A. A. (2000). Writing Errors: A Study of the Writing Ability of Arab Learners of Academic English and Arabic at University. Language Culture and Curriculum,13(2), 174-183.

Kremers, J. (2003) The Arabic noun phrase. Netherlands Graduate School of Linguistics.

Larsen-Freeman, D., and Long, M. H. (2014). An introduction to second language acquisition research. Routledge.

Löbner, S. (1985). Definites. Journal of Semantics. 4(4). 279-326.

Lobner, S. (1987). Harry C. Bunt. 1985. Mass Terms and Model-Theoretic Semantics. Studies in Language, 11(2), 469478.

Lyons, C. (1999) Definiteness. Cambridge University Press.

Marogy, A. (2004) Inversion, Definiteness, and Case Assignment in Arabic Nominal Structure. The Classical Theory. Al-'Arabiyya:': journal of the American Association of Teachers of Arabic, 77.

Mohan, B. A., and Lo, W. A. Y. (1985). Academic Writing and Chinese Students: Transfer and Developmental Factors. Tesol Quarterly, 19, 515-534.

Nariyama, S. (2003). Ellipsis and reference tracking in Japanese. John Benjamins Publishing. 
Nofal, K. H. (2011). Nouns and Adjectives of Old English and Modern Standard Arabic: A Comparative Study. International Journal of Humanities and Social Science, 1(18), 203-225.

Owens, J. (2013). The Arabic Grammatical Tradition. The Semitic Languages, 46.

Peti-Stantić, A. (2013). Informativity of Sentence Information Structure: The Role of Word Order. Language as Information. 155-178.

Reinhart, T. (1983). Anaphora and semantic interpretation. Taylor and Francis.

Renaud, F. (1996). The Definite Article: Code and Context. Journal of Semantics, 13(2), 139-180.

Retso, J. (1984). State, Determination and Definiteness in Arabic. A Reconsideration. Orientalia Suecana. 33. $341-346$.

Roberts, C. (2003). Uniqueness in Definite Noun Phrases. Linguistics and philosophy, 26(3), 287-350.

Ryding, K. C. (2005). A reference grammar of modern standard Arabic. Cambridge university press.

Saville-Troike, M. (2012). Introducing second language acquisition ( $2^{\text {nd }}$ edition). Cambridge University Press.

Schumacher, P. B. (2009). Definiteness marking shows late effects during discourse processing: evidence from ERPs. In: Anaphora processing and applications. 91-106.

Shlonsky, U. (2004). The Form of Semitic Noun Phrases. Lingua, 114(12), 1465-1526.

Sidner, C. L. (1979). Towards a computational theory of definite anaphora comprehension in English discourse (No. AI-TR-537). Massachusetts Inst of Tech Cambridge Artificial Intelligence lab.

Sigurðsson, H. Á. (2012). Minimalist C/case. Linguistic Inquiry, 43, 191-227.

Siloni, T. (2002). Adjectival constructs and inalienable constructions. In: Themes in Arabic and Hebrew syntax. 161187.

Smith, B., and Swan, M. (2001). Learner English: A teacher's guide to interference and other problems. Ernst Klett Sprachen.

Taha, K. T., Jarrah, M. A., and Al-Jarrah, R. S. (2014). The Discoursal Arabic Coordinating Conjunction Wa (And). International Journal of Linguistics 6: 172-183.

Von Heusinger, K. (2002). Specificity and Definiteness in Sentence and Discourse Structure. Journal of Semantics, 19(3), 245-274.

Von Heusinger, K. (2002). Specificity and Definiteness in Sentence and Discourse Structure. Journal of Semantics, 19(3), 245-274.

Woolford, E. (2006). Lexical Case, Inherent Case, and Argument Structure. Linguistic inquiry, 37, 111-130.

Wright, W., and Caspari, C. P. (2011). A grammar of the Arabic language. Cosimo, Inc..

Ziadeh, F. J., and Winder, R.B. (2003). An introduction to modern Arabic. Courier Dover Publications.

Zibin, A., and Hamdan, J. (2014). The acquisition of metaphorical expressions by Jordanian EFL learners: A cognitive approach. Saarbrücken: Lambert Academic Publishing.

\footnotetext{
i The term 'anchor' refers to the entities with which first-mention definite DPs may be interpreted (Fraurud 1990: 415).

ii It should be stressed that few studies have explored the role played by definiteness beyond pragmatics and semantics within current syntactic theory (cf. Wright and Caspari 2012). However, a lot of work relating to the traditional 'perspective' approaches on SA can be traced back. Here again, the main emphasis was at best descriptive, having aimed basically to numerate the cases where the definite article is used without mentioning or even speculating on the reason behind it (cf. Owens 2013).
}

iii Abney's (1987) DP theory is adopted in this research. Thus, single DPs are taken as DPs headed by a null $\mathrm{D}^{\circ}$.

iv Standard Case theory (cf. Chomsky 1981, 1986) divides Case into two types, namely: structural and non-structural, which both differ in their behavior and manner of licensing. In turn, the non-structural Cases further subdivide into two distinct types, lexical and inherent, which also differ in their behavior and manner of licensing (cf. Woolford 2006). In general, inherent Case is associated with certain theta positions, whereas structural Case is associated with the syntactic position an argument occupies (i.e., Nominative vs. Accusative) (cf. Sigurðsson 2012).

${ }^{\mathrm{v}}$ Grammaticality judgement of all SA sentences used throughout this research was made by 10 SA experts.

vi That is because $z^{\varsigma} u l m$ refers to any type of injustice.

vii Indeed, this line of thought sheds light on the mere presence of indefinite articles. Why are indefinite articles used? Logically speaking, definiteness is marked by some articles, whereas indefiniteness can be marked with the loss of definite articles (as the case of indefinite plural in English). Following our account, indefinite articles are just a way of 
materializing the head $\mathrm{D}^{\mathrm{o}}$; hence, the demand of cognition to add information about indefinite DPs is no longer invoked. However, we keep this issue open for further research.

viii This marker is assumed to be derived from the demonstrative pronoun haða used in standard Arabic through some grammaticalization process.

ix Additionally, misuse of the definite article might stimulate the hearer to exert more effort, searching for any implicit message the speaker appears to mean (see, Taha et al 2014; Al-Jarrah et al 2015; and Jarrah 2016, among others). 